\title{
Multiple side effects of penicillamine therapy in one patient with rheumatoid arthritis
}

\author{
W. K. ESSI G MAN \\ From the Lister Hospital, Corey's Mill Lane, Stevenage, Herts SG1 4AB
}

SUMMARY Skin rashes, proteinuria, systemic lupus erythematosus, polymyositis and myasthenia gravis have all been recorded as complications of penicillamine therapy in patients with rheumatoid arthritis. A patient who has developed all 5 is now described. The skin lesion resembled elastosis perforans serpiginosa, which has been reported as a rare side effect in patients with Wilson's disease but not in patients with rheumatoid arthritis treated with penicillamine.

D-penicillamine belongs to a specific or slow-acting group of drugs used in the treatment of rheumatoid arthritis. It is effective in controlling the activity of the disease in some patients, but side effects, though usually reversible, are fairly common. Some, such as loss of taste, do not necessitate any change in therapy; others, such as proteinuria or an early skin rash, necessitate the withdrawal of the drug but frequently do not recur on rechallenge. On the other hand late skin rash or myasthenia gravis constitutes an absolute contraindication to the continuation of treatment with D-penicillamine. In the patient described here proteinuria, skin lesions, and lupus syndrome did not recur after reintroduction of the drug, but the muscle disease appeared instead.

It is often stated that apart from acute hypersensitivity phenomena the incidence and intensity of a drug-induced reaction is dose-dependent. In this case the reverse appears to be true.

\section{Case report}

The patient, a male of Asian origin, presented in September 1973 at the age of 40 with a 2-month history of morning stiffness, pain in the arms, and aching of the wrists, hands, and knees. Examination showed swelling with tenderness of the proximal interphalangeal joints in both hands, limitation of movement in the wrists, and a poor grip. The erythrocyte sedimentation rate (ESR) was $74 \mathrm{~mm} / \mathrm{h}$, haemoglobin $12.7 \mathrm{~g} / \mathrm{dl}$, RA latex test positive $1 / 128$, and Rose-Waaler test positive $1 / 512$. Other routine

Accepted for publication 29 October 1981.

Correspondence to Dr W. K. Essigman. blood investigations were normal, and $x$-rays of the chest, hands, and feet did not show any abnormality either. A diagnosis of seropositive, nonerosive rheumatoid arthritis was made, and he was admitted to hospital for a period of bed rest and treatment with nonsteroidal anti-inflammatory agents.

Although his initial progress was satisfactory, the activity of the disease was not well controlled, and in January 1974 D-penicillamine was introduced in addition to standard medications, the dose being gradually increased to $900 \mathrm{mg}$ per day. During the following 4 years his disease was characterised by several exacerbations and remissions.

In November 1977 penicillamine had to be discontinued on account of proteinuria, but it was reintroduced in a daily dose of $250 \mathrm{mg}$ when the urine became albumin-free. In spite of continuous therapy with nonsteroidal anti-inflammatory agents and D-penicillamine the arthritis progressed to involve practically all joints, especially the wrists, elbows, and hands, and a few rheumatoid nodules appeared. The haemoglobin was found to be $9 \mathrm{~g} / \mathrm{dl}$; serum iron 3 $\mu \mathrm{mol} / \mathrm{l}$; total iron binding capacity $63 \mu \mathrm{mol} / 1$; levels of red cell folate and serum $B_{12}$ were normal, as were liver function tests, blood urea, creatinine, and electrolytes. Several specimens of stool were examined for occult blood and in one specimen a trace was found. Examination of bone marrow showed normoblastic hyperplasia and erythropoiesis with normal haemopoiesis and megakaryocytes; no free iron was demonstrated. A barium meal did not show any abnormality.

At this stage prednisolone $12.5 \mathrm{mg}$ was added to the other medications. Considerable improvement 


\section{Essigman}

followed, and the patient was able to return to work after a few months' incapacity. In due course it was possible to reduce the dose of prednisolone to $5 \mathrm{mg}$ per day.
In August 1979 a pruritic skin lesion resembling erythema annulare centrifugum appeared over the right shoulder and upper chest and in the right axilla (Figs. 1-3). Biopsy from the edge of one of the lesions

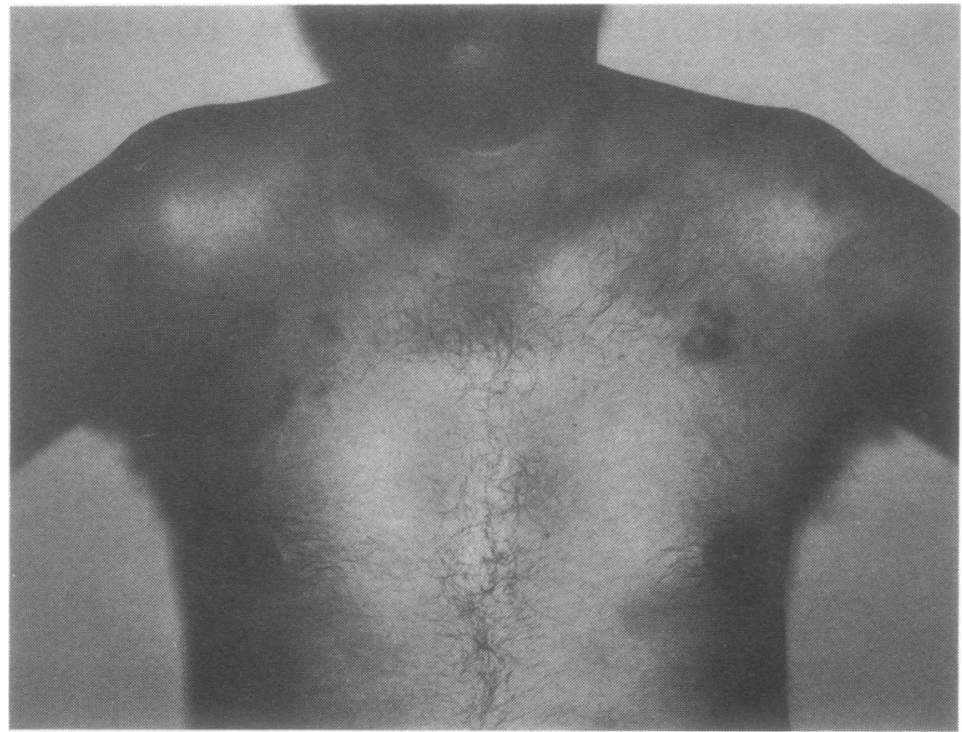

Fig. 1 Serpent-like lesion on front of chest.

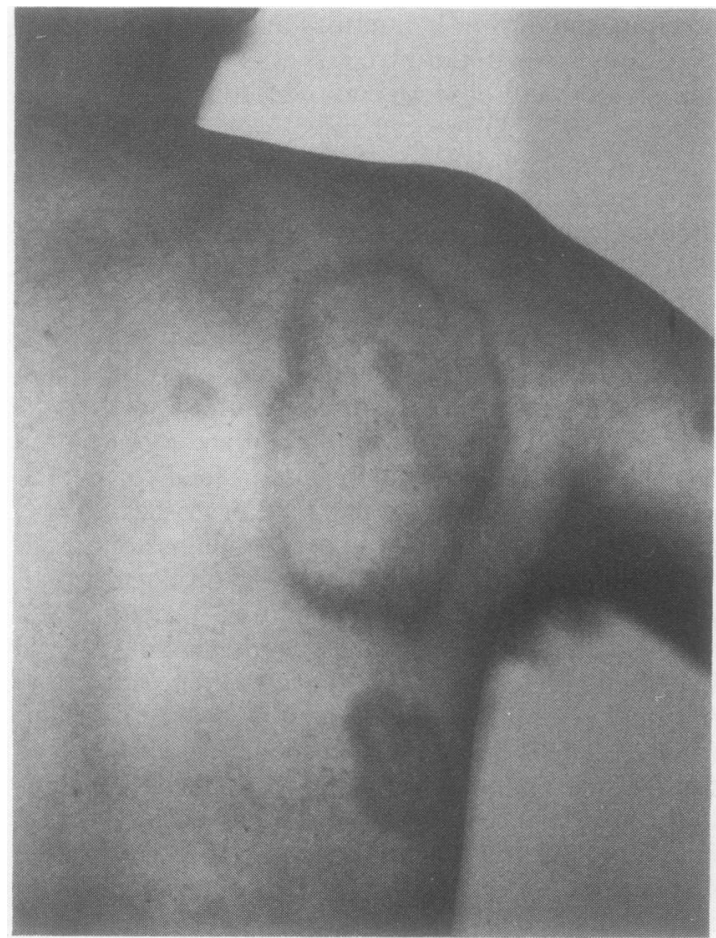

Fig. 2 Annular lesion over right scapular area.

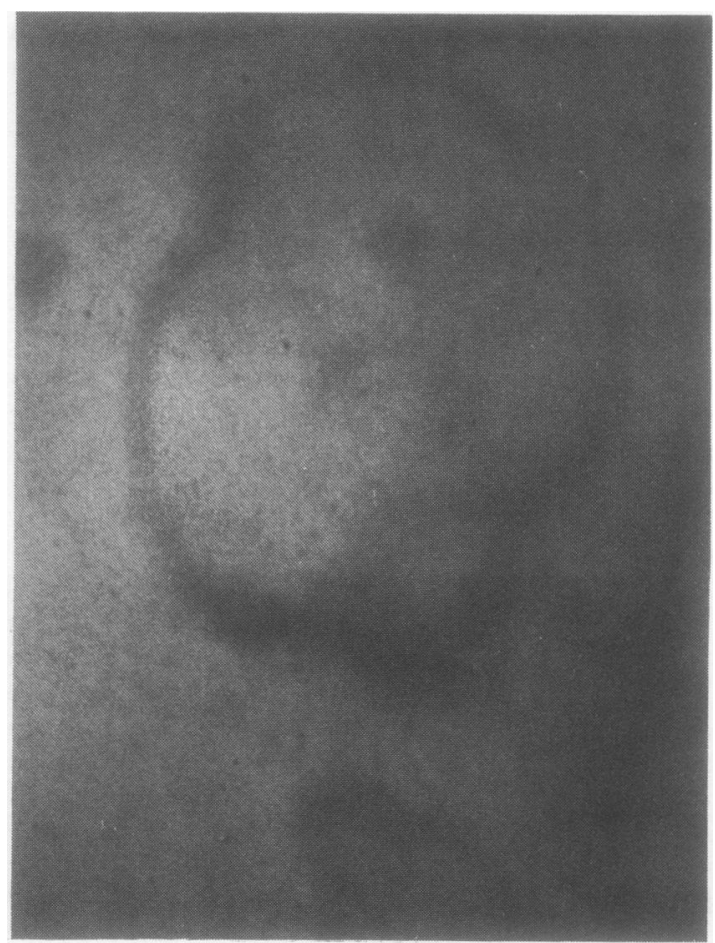

Fig. 3 Close-up of lesion over right scapular area showing arcuate appearance. 
revealed a mononuclear infiltrate in the mid-dermis, with destruction of the collagen bundles. The appearance was thought to be nonspecific but possibly representing an unusual reaction to penicillamine, which was therefore discontinued. The skin lesions gradually disappeared, and a few months later penicillamine was restarted in a daily dose of $125 \mathrm{mg}$, other medications at that time consisting of prednisolone $7.5 \mathrm{mg}$ and indomethacin $25 \mathrm{mg}$ per day.

In July 1980 the patient was admitted on account of intermittent fever during the preceding few months, poor appetite, and considerable weight loss. Investigations showed an ESR of $91 \mathrm{~mm} / \mathrm{h}$ rising to $110 \mathrm{~mm} / \mathrm{h}$; haemoglobin $14 \mathrm{~g} / \mathrm{dl}$; white cell count $10.8 \times 10^{9} / 1\left(10800\right.$ per $\left.\mathrm{mm}^{3}\right)$ with normal differential. Several blood cultures and examination of sputum were negative. No malaria parasites were seen in the blood film. Salmonella and brucella agglutination tests were normal. Antinuclear factor was positive $1 / 10$, increasing to $1 / 10240$; anti-DNA (double-stranded) antibodies were within normal range and scanty LE cells were seen in the blood film. Liver function tests were persistently raised, but liver biopsy was normal.

It was thought that the patient had developed lupus erythematosus, possibly as a complication of penicillamine therapy. This was discontinued, and when the prednisolone was increased to $60 \mathrm{mg}$ a day his temperature came down to normal within 24 hours and remained normal, ultimately allowing the dose of prednisolone to be reduced to $10 \mathrm{mg}$. However, after a few days he developed severe pain and stiffness in most of the joints, and penicillamine was started again in a dose of $250 \mathrm{mg}$ a day. His symptoms settled down very satisfactorily, and he was able to return to his usual occupation.

A few weeks after discharge from hospital he complained of some difficulty in swallowing and in talking. Penicillamine was immediately discontinued on the assumption that he had developed myasthenia gravis which was drug-induced. In spite of this his symptoms intensified. He was readmitted to hospital and found to have considerable difficulty in swallowing, right-sided ptosis, and wasting with weakness of all proximal muscle groups. Although the response to intravenous edrophonium chloride (Tensilon) was dramatic, confirming the diagnosis of myasthenia gravis, it was thought that the general muscle weakness and wasting could not be attributed to this condition alone, and the possibility of polymyositis was raised. Subsequent estimations of creatine phosphokinase showed levels varying from 700 to 1500 IU. Thyroid function tests were normal. Needle muscle biopsy from the right quadriceps muscle was very abnormal and suggestive of myositis (Dr G. R. V. Hughes, Hammersmith Hospital). Estimation of antiacetyl choline receptor antibody showed a titre of more than 71 , which is highly positive ( $\mathrm{Dr} \mathrm{J}$. N. Davis, Royal Free Hospital). The patient responded well to standard doses of neostigmine and on discharge was able to eat and talk without difficulty. The ptosis disappeared, though some proximal muscle weakness persisted. The dose of prednisolone was not increased.

When last seen in July 1981 the patient was very well, taking prednisolone $9 \mathrm{mg}$ and pyridostigmine $30 \mathrm{mg}$ daily. The ESR was $20 \mathrm{~mm} / \mathrm{h}$, haemoglobin $14 \cdot 8 \mathrm{~g} / \mathrm{dl}$, creatine phosphokinase $101 \mathrm{IU}$.

\section{Discussion}

D-penicillamine, used extensively in the treatment of rheumatoid arthritis, has been shown to control the activity of disease and delay or even arrest the progress of erosions. Unfortunately the incidence of side effects is fairly high; in some instances treatment has to be withdrawn altogether, while in others it can be restarted after a break.

Several types of skin lesions have been described as a complication of penicillamine therapy. These include an early morbilliform or maculopapular pruritic rash occurring within the first 6 months of treatment and a late rash presenting with raised, itchy, scaly lesions and sometimes taking months to disappear. Both pemphigus vulgaris and pemphigus foliaceus have been attributed to penicillamine, and mouth ulcers have also been reported in patients who have been treated with penicillamine.

In 19733 cases of elastosis perforans serpiginosa were described in young men suffering from Wilson's disease and treated with penicillamine. ${ }^{1}$ This condition presented as an arcuate, papular, itchy or slightly burning lesion, with normal skin in the centre, usually situated on the neck. Histological examination showed irregular thickening of the epidermis, infiltration by inflammatory cells, and abnormality and fragmentation of elastic tissue. These changes have been attributed to the direct action of penicillamine on the elastic component of the skin.

The patient reported here developed arcuate and annular lesions on the upper chest (Figs. 1-3), and it may well be that these are the same as the ones described by Pass et al. ${ }^{1}$ If this is correct, then it would appear that this is the first time that such a lesion has appeared in a patient with rheumatoid arthritis.

Myasthenia gravis, ${ }^{2}$ systemic lupus erythematosus, ${ }^{3}$ and polymyositis ${ }^{4}$ are now well recognised complications of penicillamine therapy, but so far each of these conditions has been reported separately in individual patients. In the case described here all 3 occurred in the same patient.

Although it is appreciated that the correctness of 
diagnosing 3 different and sometimes overlapping syndromes in the same patient may be questioned, such diagnoses appear to be justified on the strength of clinical findings and confirmed by special investigations.

Systemic lupus erythematosus. Antinuclear antibodies were present in high dilutions, LE cells were seen in blood films, and antibodies to doublestranded DNA were not detected. According to Hughes $^{5}$ the presence of LE cells and antinuclear antibodies in high dilutions together with the absence of antibodies to double-stranded DNA is a characteristic feature of drug-induced lupus erythematosus. Camus et al. ${ }^{6}$ found that, although antinuclear antibodies may be slightly positive in $34 \%$ of patients with rheumatoid arthritis, a high titre was reached only in drug-induced lupus. They are also of the opinion that the anti-DNA antibodies are not elevated in the later.

Myasthenia gravis. A dramatic response to intravenous edrophonium chloride (Tensilon) is considered to be diagnostic of this condition, and indeed such a response occurred in this patient. Furthermore, tests for antiacetylcholine receptor antibodies were highly positive.

Polymyositis. Muscle enzymes are abnormal in this condition, and the present case creatine phosphokinase was very significantly raised. Muscle biopsy also showed changes pathognomic of myositis. Although some cases of myasthenia gravis may be accom- panied by mild proximal weakness and wasting, serum enzymes are not usually elevated.

All 4 conditions from which this patient suffered in addition to rheumatoid arthritis, namely, skin rash, systemic lupus erythematosus, myasthenia gravis, and polymyositis, improved once penicillamine therapy was discontinued. This seems to support the view that all were drug-induced. It is, however, of interest that neither the skin lesion nor the lupus syndrome recurred after reintroduction of penicillamine, but muscle disease appeared instead.

I am indebted to Dr J. N. Davis, of the Royal Free Hospital, for antiacetylcholine receptor antibody assessment; to Dr G. R. V. Hughes, of the Hammersmith Hospital, for help with muscle biopsy and his encouragement to present this case for publication; and to Dr Sylvia M. Watkins for her help.

\section{References}

1 Pass F, Goldfisher S G, Sternlier I, Scheinberg I H. Elastosis perforans serpiginosa during penicillamine therapy for Wilson's disease. Arch Dermatol 1973; 108: 713-5.

2 Bucknall R C, Dixon A St J, Glick E N, Woodland J, Zutschi D W. Myasthenia gravis associated with penicillamine treatment for rheumatoid arthritis. Br Med J 1975; i: 600-2.

${ }^{3}$ Harpey J P, Caille B, Moulias R, Goust J M. Lupus-like syndrome induced by D-penicillamine in Wilson's disease. Lancet 1971; i: 292.

4 Cucher B G, Goldman A L. D-penicillamine-induced polymyositis in rheumatoid arthritis. Ann Intern Med 1976; 85: 615-6.

5 Hughes G R V. Connective tissue diseases. Oxford: Blackwell, 1977: 43.

6 Camus G P, Crouzet J, Bach J F, Homberg J C. Auto-antibodies in D-penicillamine treated patients. Agents Actions 1976; 6: 351-4. 